\title{
Rumo a uma abordagem transnacional da televisão latino-americana: Trajetórias, fronteiras e centros e periferias
}

Towards a transnational approach to Latin American television: Journeys, borders, and centers and peripheries

NA H U E R R B K E

The Open University of Israel, Department of Literature, Language and Arts. Raanana, Israel.

\section{RESUMO}

O presente artigo propõe uma abordagem transnacional histórica com o objetivo de compreender os principais padrões e desafios na produção e consumo de conteúdos televisivos na região latino-americana. Em vez de focar em casos nacionais, como fazem a maioria dos estudos sobre o campo, gostaria de destacar aqui a circulação transnacional da televisão latino-americana por meio das trajetórias e passagens de produtores, empreendedores, conteúdos e tecnologias em toda a região, dos anos 1950 até os dias atuais. $\mathrm{O}$ resultante remapeamento da televisão latino-americana nos leva a considerar que os obstáculos e barreiras linguísticas e culturais afetam a circulação de conteúdos televisivos produzidos na região, bem como as consagradas assimetrias e hierarquias de poder entre os países da região.

Palavras-chave: Televisão transnacional, história latino-americana, unidade fragmentada, plataformas de streaming, centros e periferias múltiplos

\begin{abstract}
The present paper proposes a historical transnational approach with the aim of grasping the main patterns and challenges in the production and consumption of television contents in the region. Instead of focusing on national cases, as most studies on the field do, I would like to focus here on the transnational circulation of Latin American television through the journeys and passages of producers, entrepreneurs, contents, and technologies across the region from the 1950s to the present. The resulting remapping of Latin American television prompts us to consider the linguistic and cultural obstacles and barriers affecting the circulation of television contents produced in the region as well as the established power asymmetries and hierarchies among Latin American countries. Keywords: Transnational television, Latin American history, fragmented unity, streaming platforms, multiple centers and peripheries
\end{abstract}


$\mathrm{R}$ EVISITAR QUESTÕES SOBRE os traços definidores da televisão latino-americana em um momento em que a estabilidade das fronteiras ções radicais pode não parecer, à primeira vista, a abordagem mais adequada para a compreensão do atual cenário midiático na região. Embora a intersecção dos processos econômicos, culturais e políticos mundiais tenha contribuído para a erosão das identidades nacionais e regionais, as mudanças tecnológicas na produção e no consumo de conteúdos audiovisuais romperam os limites de práticas culturais bastante consagradas. Não só os espectadores, mas também nós, estudiosos, podemos nos sentir desconfortáveis quando indagados sobre como definimos o que é televisão ou cinema, hoje. Apesar dos desafios que essa conjuntura coloca para fazer afirmações teóricas sólidas, gostaria de defender neste artigo que revisitar a história da televisão na América Latina pode nos fornecer algumas ferramentas para compreender os principais padrões e desafios na produção e no consumo da televisão nessa região. Em lugar de focar em casos nacionais, como fazem a maioria dos estudos sobre o campo, gostaria de focar na circulação transnacional da televisão latino-americana por meio das trajetórias e passagens de produtores, empreendedores, conteúdos e tecnologias por toda a região, dos anos 1950 até os dias atuais. Para isso, proponho entrelaçar as micro-histórias de produtores, técnicos e criadores pioneiros da TV com a história política e econômica da região e do mundo desde a segunda metade do século XX.

\section{SOBRE AS TRAJETÓRIAS DE EMPREENDEDORES, TECNOLOGIAS E PRODUTORES DE CONTEÚDO}

Em lugar de enquadrar o consumo audiovisual atual via TV a cabo e plataformas de streaming como uma ruptura com o passado, argumento que várias características definidoras que marcam o novo ecossistema de mídia de entretenimento já estavam presentes desde os primórdios da televisão na região. Vamos começar nossa história com as trajetórias de empreendedores pioneiros da mídia para importar a tecnologia de televisão e know-how dos Estados Unidos. Várias histórias nacionais da televisão enfatizam a capacidade visionária de empresários e investidores locais, a criatividade de profissionais de rádio e de artistas que migraram para a televisão e como os técnicos autodidatas aprenderam seu ofício no trabalho. No entanto, os contextos internacionais e transnacionais da chegada da televisão para a região permanecem à margem dessa narrativa. Acadêmicos críticos que escreveram durante as décadas de 1960 e 1970 enfatizaram os aspectos intervencionistas do translado da televisão para 
a região, mas deve-se notar que sua crítica foi enquadrada em um argumento mais geral e abrangente sobre como o processo de modernização da América Latina estava se desenrolando dentro de um sistema capitalista (Beltrán \& Fox, 1980; Mattelart, 1973; Melo, 1987). Apesar de suas afirmações convincentes, essa crítica ao imperialismo midiático não abordou a natureza contraditória e complexa do cenário midiático da região. Apresentar uma narrativa dicotômica sobre o impacto dos EUA no panorama midiático da América Latina foi uma ferramenta política pedagógica bastante eficaz, mas conduziu a uma negligência sobre as transformações nos equilíbrios de poder entre centros e periferias dentro e fora da região.

Recuperar uma micro-história da chegada da televisão ao México, Brasil e Argentina no início da década de 1950 pode nos dar uma perspectiva mais completa sobre a dinâmica interna envolvendo a indústria televisiva na região. Essa dinâmica interna criou um sistema de mídia latino-americano que é - também, mas não exclusivamente - moldado por seu relacionamento assimétrico com os Estados Unidos. Encorajados pelo establishment político local e abraçando uma retórica abertamente nacionalista, os empreendedores regionais embarcaram em uma competição para serem os primeiros a levar a televisão e a modernidade para as suas nações (Castro, 2000, p. 20; González de Bustamante, 2012, pp. 1-26; Sinclair, 1998, p. 14; Varela, 2005, pp. 13-44). "Qual país latino-americano seria o primeiro a lançar a transmissão de TV?”, “o que isso diz sobre nós que fomos deixados para trás na corrida pela transmissão nacional?”. Essas são algumas das perguntas que foram feitas com frequência na imprensa popular durante a década de 1950. A concorrência regional entre os empresários latino-americanos contrariou o conselho dos gestores de empresas dos Estados Unidos que estavam relutantes com as perspectivas de exportar um sistema de mídia tão caro para nações com pequenos mercados consumidores (Machado de Assis, 2000, p. 20).

Voltando à indagação principal sobre como uma abordagem transnacional pode nos ajudar a entender a mídia e os cenários cultural e político da região atualmente, devemos perguntar: o que podemos aprender com essa história inicial? Embora seja inegável que as tecnologias de mídia contemporânea têm provocado uma ruptura nos padrões de produção e distribuição audiovisual na região, a chegada da Netflix nos mostra atitudes e abordagens semelhantes às que mencionamos anteriormente. A Netflix é um serviço de streaming on-line com sede nos EUA, e chegou à América Latina em 2011, em um estágio muito inicial de sua expansão global. Assim como os profissionais da televisão dos EUA fizeram na década de 1950, no início da segunda década dos anos 2000, especialistas alertaram sobre a falta de infraestrutura adequada de internet nos países latino-americanos e sobre o fato de que grande número dos domicílios 
na região não tinha acesso a uma conexão de banda larga (Cornelio-Marí, 2020, pp. 1-17; Fraga, 2011; Muñoz, 2011). Assim como a televisão meio século antes, a Netflix era vista como uma prova de modernidade e desenvolvimento que foi, e talvez ainda seja, medida através de métricas quantitativas, como o número de assinantes por país, o número de produções originais por país disponibilizadas por plataformas globais de streaming e o alcance e a qualidade dos serviços de banda larga em cada país (Andro4ll, 2019; Sanchez, 2019).

Embora a chegada da tecnologia e do know-how comercial necessários para a televisão pudesse ser explicada principalmente pelos laços políticos, econômicos e culturais da região com os EUA, o desenvolvimento dos gêneros e conteúdos latino-americanos mais distintos, como a telenovela e os programas de variedades, deve ser entendido principalmente em termos de dinâmicas políticas, econômicas e culturais internas da região. A situação política e econômica volátil da região durante as décadas de 1960 e 1970 provocou, ou forçou, conforme se prefira, a trajetória de produtores de televisão, trabalhadores criativos e técnicos que trouxeram consigo know-how, práticas e ideias que disseminaram por toda a região. Esse movimento e a circulação de profissionais da televisão - às vezes como exilados - foram insuficientemente pesquisados, apesar do impacto que tiveram no desenvolvimento da indústria televisiva na região. A televisão latino-americana teria tido a mesma trajetória sem o impacto de revoluções, golpes militares e crises econômicas e políticas que afetaram a região desde a década de 1950 até hoje?

Apesar de algumas referências na literatura acadêmica aos gestores latino-americanos da televisão e aos profissionais que trabalharam no Brasil e na Argentina, a história da diáspora cubana e seu papel no desenvolvimento da televisão na região antes e depois da revolução ainda não foram escritas. No Brasil, as referências a Glória Magadan, a escritora cubana que trabalhou para a Globo durante os primeiros anos da emissora, são frequentemente descritas como uma anedota menor que impede uma análise mais profunda sobre a transferência de know-how para a produção televisiva. Se observarmos esta história a partir da nossa atual consciência da dinâmica de gênero, poderíamos argumentar que ser uma mulher (estrangeira) e trabalhar no que era considerado como um gênero menor provavelmente afetou a percepção de seu papel na adaptação das telenovelas cubanas para o solo brasileiro. Talvez tenha contribuído para essa omissão o fato de que ex-produtores (homens) de televisão brasileiros estiveram e ainda estão envolvidos na escrita de histórias e de memórias sobre esse período (Clark \& Priolli, 1991, p. 37; "Glória, Ditadora das Novelas", 1969, p. 62; Oliveira, 2011, pp. 138-144). Na Argentina, há uma biografia relativamente curta e pouco documentada a respeito do magnata da 
mídia cubano Goar Mestre (Sirvén, 1996). Ainda não se sabe muito sobre o grupo de técnicos e profissionais de TV que ajudaram na criação e na formação do Canal 13, com sede em Buenos Aires, cuja marca na televisão argentina perdura até hoje. A chegada da diáspora televisiva cubana ao Cone Sul ocorreu devido a acordos mais ou menos abertos, a parcerias entre os proprietários da mídia local e emissoras e as gestões dos meios de comunicação estadunidenses que buscavam oportunidades para expandir seus negócios em todo o mundo (Herz, 1987; Sinclair, 2005). Este exemplo pode levar à questão as tentativas frequentes de compartimentar o nacional, o regional e o global ao analisar a história da televisão na América Latina desde seus primórdios.

Mas, além da revolução cubana, também temos indicações claras de outros movimentos cruciais e de viagens de trabalhadores da televisão que ocorreram como resultado da turbulência política e econômica que a maioria dos países da região experimentou nos últimos setenta anos. Este foi o caso de David Stivel, um produtor argentino de teatro e televisão que escapou da Argentina pouco antes do golpe militar de direita de 1976 e desenvolveu uma fecunda carreira na televisão colombiana como diretor de telenovelas e programas de TV (Coronado, 1992, pp. 290-291; Gutierrez, 2007). De posição ideológica oposta, Joaquin Blaya, o executivo de mídia chileno que trouxe o apresentador chileno Don Francisco para a televisão hispânica dos EUA, deixou o Chile no início dos anos 1970 por receio do presidente chileno de esquerda eleito democraticamente Salvador Allende (Kreutzberger, 2001, pp. 17-19; Owens, 1988 , p. 1). Apesar ou por causa do atual ecossistema de mídia, no qual tecnologias de comunicação, profissionais audiovisuais e conteúdos viajam pelo mundo mais rápido do que em períodos anteriores, a política latino-americana e global provavelmente continuará a ter um papel significativo na produção de conteúdo televisivo em todo o subcontinente. A transformação da Colômbia em um centro regional de produções internacionais de cinema e televisão nos oferece um exemplo contemporâneo de como a política local, nacional, regional e internacional altera e molda as indústrias cinematográficas e televisivas da região. A ascensão da Colômbia foi favorecida pelas políticas do governo nacional que concedem incentivos para as indústrias de comunicação, mas também, e talvez principalmente, pelo processo de paz iniciado em 2012. Paradoxalmente, Narcos (Brancato et al., 2015-2017), série de TV da Netflix sobre o traficante colombiano Pablo Escobar, representa as oportunidades que foram abertas para os produtores locais pelo processo de paz em curso e, ao mesmo tempo, a transformação dessa dolorosa história nacional em uma série de ficção de entretenimento que reforça estereótipos para atrair a audiência internacional (Ribke, 2020b, pp. 103-106). 


\section{SOBRE AS FRONTEIRAS LINGUÍSTICAS, ECONÔMICAS E HISTÓRICAS DO SISTEMA DE TELEVISÃO LATINO-AMERICANO}

Se na seção anterior defendemos a existência de um cenário televisivo latino-americano, devemos agora perguntar sobre seus limites e fronteiras. Quais países estão incluídos nesse sistema? Quais são deixados para trás? Assim como a ideia da América Latina como entidade cultural e política distinta tem sido reforçada e promovida pelas obras de intelectuais, escritores e políticos desde o século XIX, a mídia de massa e a televisão funcionam como catalisadores na produção de uma identidade latino-americana compartilhada por meio da circulação transnacional de personalidades e conteúdos televisivos em toda a região. Em um momento de extrema euforia, o apresentador de TV chileno Don Francisco declarou que seu programa de variedades, transmitido pela rede hispano-estadunidense Univision e disponibilizado por redes de TV a cabo em todo o continente, "materializou, por meio da pequena tela, o sonho de Simón Bolivar de unificar o continente americano" ("Diez Años", 1996, p. 4). Embora alguns leitores possam ficar escandalizados pela forma como o apresentador coloca no mesmo nível Simón Bolivar e José Martí juntamente com Don Francisco e El Chavo del Ocho (Chaves, no Brasil), creio que devemos levar a sério a ideia de que a televisão tem desempenhado um papel na formação de uma identidade latino-americana transnacional e de um repertório de cultura popular regional compartilhado que existe lado a lado com as identidades nacionais. Essa identidade transnacional latino-americana é estimulada por produtores de mídia e anunciantes que estão interessados em criar mercados maiores para seus produtos (na maioria das vezes estrangeiros), mas também por receptores de toda a região que se sentem interpelados por esses conteúdos populares.

Seguir os fluxos de conteúdos produzidos e consumidos poderia fornecer um mapa mais preciso da região. Nesse sentido, os relatórios anuais da Obitel sobre a ficção televisiva ibero-americana nos oferecem pistas significativas para um estudo transnacional da televisão na região, pois incluem conteúdos e audiências localizados além das fronteiras oficiais, como os Estados Unidos, a Espanha e Portugal. As fronteiras internas, ocultas, da paisagem midiática latino-americana podem revelar mais sobre a região do que seus limites externos. Por isso, nesta seção, quero refletir sobre as fronteiras, as barreiras e as passagens que os conteúdos televisivos produzidos na região encontram ao viajar por esse território.

A primeira questão a ser levada em conta é que alguns gêneros e conteúdos normalmente trafegam pela região, enquanto outros permanecem restritos à esfera da televisão nacional. $\mathrm{O}$ gênero telenovela tende a ser considerado como um viajante frequente. Outros conteúdos televisivos, como as notícias, os 
programas humorísticos e os programas de atualidades dirigem-se ao público nacional. Os variety shows (programas de auditório, no Brasil, e programas ómnibus, na Argentina) foram, e talvez ainda sejam, um gênero latino-americano extremamente popular que quase sempre é esquecido nas pesquisas sobre televisão. Apesar de sua estética muitas vezes bizarra e seus polêmicos apresentadores, os programas de auditório em toda a região serviram como plataforma extremamente eficaz para a criação de um sistema de estrelas da música popular/pop latino-americana e para a disseminação de ritmos e gêneros musicais locais. Talvez essa falta de pesquisa sobre esse gênero televisivo possa ser explicada pelo fato de que os programas de auditório não foram exportados, mas sim concebidos como entretenimento ao vivo de baixo orçamento para consumo imediato. O olhar arrogante em relação aos valores das classes sociais representadas nesses programas também pode ter contribuído para a falta de interesse dos estudiosos da mídia pelo gênero (Ribke, 2013).

Apesar da caracterização frequente da América Latina como uma região distinta com uma linguagem comum e um passado colonial compartilhado, devemos estar cientes de que os diferentes idiomas podem constituir um obstáculo para a circulação de conteúdos audiovisuais na região. As barreiras linguísticas podem afetar a circulação de programas de televisão nacionais em toda a região, devido a razões conjunturais históricas, políticas e econômicas. Os maiores e mais ricos mercados da região têm uma indústria de mídia local vibrante e poderosa que, ao longo dos anos, vem oferecendo ao público nacional conteúdo local, criando hábitos de visualização que desencorajaram o consumo de conteúdo estrangeiro. Segundo John Sinclair (1998, p. 16), o status do espanhol mexicano na região é comparável ao do inglês estadunidense na região geolinguística anglófona. Enquanto o público mexicano é resistente a outras produções em língua espanhola, o público latino-americano é receptivo às produções mexicanas porque foram expostos por várias décadas a programas de TV mexicanos que circularam pela região. Além do tamanho do mercado brasileiro e de sua poderosa economia, a língua portuguesa também tem funcionado como uma barreira natural ao fluxo de conteúdos de televisão produzidos em outros paises da região.

Mas as barreiras linguísticas que dificultam a importação de conteúdo televisivo da região não impediram que as telenovelas brasileiras se tornassem um grande sucesso entre o público latino-americano. Assim como o impacto mundial da indústria audiovisual dos EUA, as produções brasileiras são atraentes para o público nos países vizinhos de língua espanhola devido aos valores advindos do alto orçamento delas. A exibição das telenovelas brasileiras na televisão uruguaia em detrimento das produções argentinas é um exemplo da 
prevalência dos valores de produção sobre a proximidade cultural. Em alguns casos, países da região com aspirações de desenvolver suas próprias indústrias audiovisuais podem tender a enfatizar demais as diferenças entre seu próprio estilo de espanhol e o de seus vizinhos, a fim de proteger suas incipientes indústrias cinematográficas e televisivas. O caso da telenovela argentina Esperanza Mía (Suar, 2015-2016), produzida pela Pol-ka e distribuída pela Dori Media Productions, nos oferece um excelente exemplo de como as barreiras linguísticas podem ser artificialmente criadas por razões econômicas e/ou políticas. As emissoras chilenas que compraram o programa argentino decidiram dublá-lo em espanhol chileno, em uma decisão que enfureceu os telespectadores chilenos, que reclamaram da intervenção desnecessária das emissoras locais e dos efeitos nocivos da dublagem em sua experiência de consumo ("CHV Explica", 2016). Apesar da escassez de pesquisas sobre o tema, há indícios de que as rivalidades internas e a concorrência entre os países latino-americanos podem afetar a distribuição e o consumo de conteúdos audiovisuais produzidos na região. Essa rivalidade ou concorrência interna poderia ser induzida pelas estratégias de mercado atuais ou, por exemplo, pela história política e militar de longo prazo da região, capaz de moldar atitudes e temores entre os países regionais vizinhos. O Chile e a Argentina possuem disputas fronteiriças de longa data que quase causaram uma guerra entre os países no final da década de 1970 (Garret, 1985; Villar Gertner, 2014). De que forma os conflitos passados e as rivalidades sobre fronteiras geográficas afetam o consumo de conteúdos audiovisuais intra-regionais? Como os alinhamentos geopolíticos internacionais dos países latino-americanos afetam a circulação intra-regional e o consumo de conteúdos audiovisuais?

Se a rivalidade interna pode representar barreiras à circulação interna de conteúdos regionais, os traços culturais, sociais e políticos comuns dos países latino-americanos são frequentemente citados como explicações para os padrões regionais de consumo de conteúdo de entretenimento midiático produzido externamente. O caso das telenovelas turcas (também conhecidas como dizi) que invadiram as pequenas telas latino-americanas desde 2014 são um exemplo de padrões regionais de consumo audiovisual e tendências culturais que muitas vezes são negligenciados. As séries dramáticas turcas desembarcaram na região em uma etapa relativamente tardia, quase uma década depois de terem tido sucesso global. A predominância das telenovelas latino-americanas em toda a região e a distância cultural entre os países latino-americanos e a Turquia poderiam explicar a relutância dos gestores de televisão latino-americanos quando lhes foi oferecida a compra das séries de TV turcas. Patricio Hernandez, o recém-chegado CEO da Mega Network chilena, que tomou as rédeas no meio de uma 
enorme crise econômica e de audiência, decidiu comprar a série turca Binbir Gece (Avci, 2006-2009) (veiculada como Las Mil y Una Noches) como medida temporária de emergência para ganhar tempo enquanto a emissora preparava uma nova grade de programação (Chamy, 2014; PRODU, 2016). O surpreendente sucesso comercial e de audiência de Binbir Gece no Chile provocou um efeito contagioso em toda a região e as redes nacionais começaram a comprar séries de televisão turcas e a exibi-las em horário nobre, principalmente às custas de séries de ficção locais e regionais. O sucesso dos dramas turcos na Argentina afetou funcionários da $\mathrm{TV}$, atores, diretores e roteiristas que reclamaram dos efeitos negativos de um mercado de mídia não regulamentado na indústria audiovisual local (Cruz, 2015). Paradoxalmente, o sucesso das dizis na Argentina, país conhecido por seu exigente público, encorajou outras redes de televisão latino-americanas a comprar dramas turcos, em detrimento de produções locais e exportações intra-regionais de ficção televisiva (Joacogarau, 2015). De modo não surpreendente, México e Brasil, as principais economias e produtores de mídia da região foram menos afetados pela onda turca justamente por estarem menos inclinados a consumir conteúdos produzidos por seus países vizinhos (Vassallo de Lopes \& Greco, 2016). O México e o Brasil são capazes de manter altos padrões de produção mesmo durante períodos de crise econômica devido à relativa força de suas economias e ao tamanho de seus mercados. Além disso, suas audiências desenvolveram hábitos de consumo profundamente enraizados, relacionados aos conteúdos de televisão nacional.

O que podemos aprender sobre a região a partir da nossa discussão sobre as fronteiras do sistema de televisão latino-americano? Se existe um sistema de televisão latino-americano, este pode ser caracterizado como uma unidade fragmentada ou uma integração ambivalente. Enquanto cada nação e cada indústria audiovisual definem sua identidade e seus objetivos em relação ao país vizinho, o consumo de conteúdos audiovisuais de fora da região pode ser estabelecido em termos regionais. Em outras palavras, as emissoras latino-americanas parecem estar mais propensas a seguir o padrão de compra de conteúdo extra-regional de seus países vizinhos, enquanto às vezes são mais relutantes em comprar produtos desses vizinhos com os quais compartilham gostos semelhantes com relação a suas audiências.

\section{SOBRE OS MÚLTIPLOS CENTROS E PERIFERIAS DO SISTEMA DE TELEVISÃO LATINO-AMERICANO}

Se a seção anterior se concentrou em diferentes níveis de obstáculos encontrados pelos conteúdos audiovisuais produzidos na região ao percorrer suas 
fronteiras internas, a atual refletirá sobre os múltiplos centros e periferias que moldam a produção e o consumo de televisão na região. Enquanto nas primeiras quatro décadas de televisão era possível descrever o público nacional e as indústrias audiovisuais nacionais em termos estruturais substanciais, apesar de falhas metodológicas significativas e imprecisões, hoje esse movimento parece muito mais problemático. A definição de Straubhaar $(1991,2007)$ da paisagem de mídia (mediascape) emergente como refletindo uma interdependência assimétrica dinâmica que excede o estado-nação como unidade de análise exclusiva e relevante ainda é precisa ao refletir sobre o sistema latino-americano contemporâneo. No entanto, ainda temos que explicar como essa interdependência assimétrica se materializa através de redes complexas compostas por centros e periferias localizados ao longo e além dos limites formais da região.

Muitos dos conteúdos nacionais de televisão de entretenimento produzidos hoje consistem em formatos comprados de produtores de dentro e de fora da região adaptados para o público nacional. Os países produtores de TV mais ricos da região - como o México, o Brasil e a televisão hispânica dos EUA - são mais propensos a comprar e adaptar formatos de TV de produtores audiovisuais latino-americanos menos poderosos, como a Argentina e a Colômbia. Além de agregar valores de produção mais elevados do que as versões originais, por serem as principais compradoras de formatos de TV, as empresas de mídia mais poderosas da região conseguem se transformar nas proprietárias do formato, lucrando com as vendas internacionais. O caso do superformato colombiano Yo Soy Bety, la Fea, é ilustrativo da relação assimétrica entre os criadores colombianos e os produtores e distribuidores mexicanos (Rivero, 2012; Sinclair, 2014).

Os países latino-americanos com mercados e indústrias audiovisuais menores tendem a comprar os programas enlatados produzidos nos países mais ricos da América Latina para preencher sua programação diária. Essa não é uma tendência totalmente nova no sistema de televisão latino-americano, mas o ecossistema midiático contemporâneo, constituído por redes globais de TV a cabo e streaming que oferecem um imenso volume de programas, tende a desencorajar o investimento dos países menores e médios em produções locais. Estabelecer parcerias com empresas internacionais de mídia e investidores estrangeiros é uma alternativa viável para as indústrias audiovisuais menos ricas da região, mas essa opção tem um custo. Embora as parcerias internacionais ajudem a aumentar as capacidades de produção e as habilidades técnicas dos trabalhadores da mídia local, os projetos são aprovados para financiamento de acordo com seu potencial apelo ao público internacional. A produção de séries de ficção com um excesso de sabor local (produzido), narrando histórias de crime, corrupção e pobreza pode parecer aos produtores e investidores locais e internacionais 
um meio atraente para conquistar o público global. As séries de ficção que são distribuídas e/ou produzidas por empresas de mídia globais e plataformas de streaming e retratam traficantes latino-americanos famosos, músicos populares e jogadores de futebol carismáticos são exemplos dessa fórmula em evolução (Ribke, 2020b, capítulo 7).

Se pensadores críticos das décadas de 1960 e 1970 apontavam para os padrões de dependência dos países latino-americanos em relação às potências globais, como os Estados Unidos e as antigas potências coloniais europeias, a análise do sistema de televisão latino-americano aponta para hierarquias intra-regionais e relações de poder entre centros de produção de mídia e países que importam conteúdo midiático. No cenário da mídia latino-americana, existem dois principais países produtores de mídia, alguns produtores de médio porte e muitos países periféricos. Embora o lugar do Brasil e do México como produtores centrais tenha sido constante desde a década de 1970, outras indústrias de mídia da região sofreram mais seriamente o impacto da instabilidade econômica e política. O caso da Venezuela, outrora um dos principais exportadores regionais que parou de produzir telenovelas mesmo para o seu mercado interno, e a ascensão do mercado hispânico dos EUA como consumidor regional e produtor de conteúdo televisivo é ilustrativo da mutável dinâmica do campo mediatico latino-americano (Acosta-Alzuru, 2021; Allen, 2020).

A liderança regional do Brasil e do México na produção de conteúdo midiático tem desdobramentos econômicos geoculturais que exigem a reformulação das abordagens tradicionais dos centros e periferias. A expansão do conglomerado da mídia brasileira Globo na Europa, ocorrida em meados da década de 1980, pode lançar algumas luzes interessantes sobre as oportunidades e limites para a reversão dos padrões de fluxos de mídia entre centro e periferia. Apesar de seu pesado investimento na expansão para o mercado italiano e, em seguida, para a Europa continental, através da Telemontecarlo Television, o projeto da Globo sofreu perdas econômicas significativas que colocaram todo o conglomerado de mídia em sério risco. Ao contrário de seu fracasso no mais abastado mercado de televisão italiano, a Rede Globo encontrou um ambiente muito mais propício para seus esforços de expansão internacional em Portugal, sua antiga metrópole colonial, mas hoje um mercado pequeno e muito menos lucrativo (Ribke, 2020a; Sousa, 1997).

O envolvimento de magnatas da mídia mexicana, profissionais de TV e artistas no mercado de televisão dos EUA aponta para um relocalização ou realocação de capacidades produtivas, parcerias e investimentos que não poderiam estar restritos à esfera nacional. $\mathrm{O}$ envolvimento de empresas de mídia e produtores de televisão mexicanos deteve a expansão da Rede Globo nos EUA, levando o 
grupo a realizar uma operação mais arriscada em solo europeu (Ribke, 2020a; Wallach, 2011). Ao mesmo tempo, as expressivas capacidades de produção e os recursos econômicos das emissoras mexicanas obstruíram a criação de emissoras de mídia latinas e de conteúdos destinados à população latina no mercado de televisão nos EUA. De acordo com estudiosos da mídia que analisam a televisão hispânica estadunidense, os cálculos econômicos sobre a necessidade de criar maiores audiências e a disponibilidade de um grande estoque de conteúdos televisivos trabalharam contra o surgimento de produtos de televisão locais capazes de refletir a complexa e heterogênea identidade cultural e étnica das populações de língua espanhola que vivem nos EUA (Dávila, 2012; Mora, 2011; Turow, 1997). Poderíamos caracterizar o envolvimento mexicano no mercado de televisão hispânico dos EUA como uma forma de imperialismo cultural?

Um padrão semelhante de relações assimétricas entre centros e periferias ocorre dentro dos estados-nação. As empresas produtoras de mídia, as emissoras e os profissionais de televisão e publicidade estão localizados principalmente nas capitais políticas, culturais e econômicas e os conteúdos televisivos que produzem refletem uma cultura e valores de consumo mais cosmopolitas e modernos que distorcem, perturbam e até colidem com os valores e estilo de vida das populações periféricas que vivem nos países da América Latina como um todo. Ao invés de entender a audiência periférica como consumidores passivos e reprodutores dos padrões e valores culturais promovidos pelos centros políticos e econômicos nacionais, diversos estudos apontam para um papel mais ativo do público que pode se engajar na busca por produtos televisivos compatíveis, além das fronteiras culturais e linguísticas nacionais. A preferência dos telespectadores brasileiros localizados em comunidades rurais e cidades periféricas do Brasil por telenovelas mexicanas e/ou séries dramáticas turcas é um significativo exemplo da reconfiguração e da fragmentação das audiências (Ferreira, 2017; La Pastina \& Straubhaar, 2005).

\section{CONSIDERAÇÕES FINAIS}

Apesar ou justamente devido às mudanças radicais na forma como assistimos e discutimos a televisão - algumas dessas novas tendências tornaram-se ainda mais drásticas após dois anos de uma pandemia global -, este artigo propôs revisar a história da televisão na América Latina para questionar e refletir sobre o campo midiático contemporâneo na região. A proposta do artigo é sugerir uma leitura da produção e do consumo de televisão na América Latina como um sistema de televisão transnacional que foi e continua a ser moldado pela política regional e global, pelas diferenças linguísticas e culturais que afetam 
a circulação de conteúdos televisivos na região e por assimetrias de mercado entre as nações latino-americanas.

A discussão da política regional e global na formação de um sistema de televisão latino-americano transnacional tem dois objetivos principais. $\mathrm{O}$ primeiro é clamar por uma compreensão mais profunda e séria do impacto dos processos econômicos e políticos no desenvolvimento das indústrias culturais regionais. As revoluções, os conflitos, as intervenções militares na política e a instabilidade econômica na região operaram como forças centrífugas na formação da indústria televisiva regional. Embora a realocação de exilados políticos e econômicos de profissionais da televisão careça da aura romântica e/ou heroica de ativistas políticos perseguidos ou figuras culturais renomadas da região, esses movimentos e deslocamentos tiveram um enorme impacto no desenvolvimento do repertório da cultura popular/massiva latino-americana. O segundo objetivo é conectar a televisão latino-americana com a política regional e global, convocando os estudiosos da história a incluir a análise da televisão como um campo histórico extremamente importante na segunda metade do século XX.

As fronteiras linguísticas, culturais e econômicas e os obstáculos que restringem ou facilitam a circulação de conteúdos televisivos podem nos levar a refletir sobre as características estruturais que definem a América Latina em geral e o sistema de televisão latino-americano em particular. Apesar da muito citada homogeneidade linguística, religiosa e cultural da região, a circulação e o consumo de conteúdos televisivos produzidos na região são desestimulados por barreiras culturais, econômicas e históricas reais e, por vezes, fabricadas entre os países latino-americanos. As indústrias de mídia mais poderosas da região enfrentam menos obstáculos ao atravessar fronteiras nacionais devido ao maior valor de produção de seus produtos. Ao mesmo tempo, enfrentam menos concorrência em seus mercados internos, porque suas audiências desenvolveram hábitos de audiência profundamente enraizados à televisão local. No entanto, conflitos históricos, rivalidades locais e a disposição de desenvolver suas próprias indústrias de mídia podem dificultar uma circulação mais ampla de conteúdos audiovisuais produzidos por países menores da região. Paradoxalmente, os produtos audiovisuais estrangeiros se beneficiam da relativa homogeneidade cultural e linguística da região, e programas de televisão que são bem-sucedidos em um país rapidamente se espalham pelo continente. Proponho definir o sistema de televisão latino-americano (e talvez a América Latina como um todo) como caracterizado por uma unidade fragmentada ou uma integração ambivalente, na qual o consumo intrarregional é menos frequente e menos homogêneo do que o consumo extrarregional de conteúdos audiovisuais. 
Generalizações sobre as indústrias de mídia latino-americanas e comparações com as de outras regiões geoculturais do mundo podem muitas vezes levar a distorções e imprecisões em relação às complexas redes de produção e consumo na região e fora dela. Para evitar essas falácias, precisamos olhar para as complexas redes de trocas entre os produtores de mídia nos mercados de mídia mais desenvolvidos da região e nações e mercados menores. O Brasil e o México foram e ainda são as principais forças do sistema de televisão latino-americano, mas este cenário está longe de ser estático. Embora os padrões intrarregionais de intercâmbios entre as indústrias televisivas reflitam interdependências assimétricas, devemos evitar olhar para produtores e audiências em mercados menores como atores passivos no jogo de mercado regional e global. Os incentivos governamentais, o desenvolvimento de estratégias criativas e o estabelecimento de parcerias internacionais por produtores de indústrias midiática médias e pequenas podem atenuar, se não contornar, totalmente as assimetrias econômicas. Do ponto de vista das audiências, o novo ecossistema global de mídia oferece a possibilidade de que os telespectadores de regiões periféricas dentro dos países da América Latina deixem de consumir os produtos de televisão das capitais centrais do país e procurem conteúdos que representem valores semelhantes e uma estrutura de sentimento mais próxima. Como os centros tradicionais de produção de mídia na América Latina se acomodarão a esse novo ambiente de mídia global e que tipo de padrões de produção e consumo surgirão na região? Ainda poderemos chamar essa rede emergente de sistema de televisão latino-americano? $\mathbf{M}$

\section{REFERÊNCIAS}

Acosta-Alzuru, C. (2021). From riches to rags: The decline of Venezuelan telenovelas. In E. Korin \& P. Pain (Eds.), When media succumbs to rising authoritarianism (pp. 61-76). Routledge.

Allen, C. (2020). Univision, Telemundo, and the rise of Spanish-Language television in the United States. University Press of Florida.

Andro4ll. (2019, 23 de julho). México, segundo lugar en suscripciones a Netflix a nivel mundial, entre Brasil y Argentina. La Vanguardia. https://bit.ly/3eIIiOI

Avci, E. (Produtor executivo). (2006-2009). Binbir gece [Mil e uma noites] [Telenovela]. TMC.

Beltrán, L. R., \& Fox de Cardona, E. (1980). Comunicación dominada: Estados Unidos en los medios de América Latina. Nueva Imagen. 
Brancato, C., Bernard, C., Miro, D., O'Connell, K., Newman, E., Padilha, J., \& Ellis, E. T. (Produtores executivos). (2015-2017). Narcos [Série de televisão]. Gaumont International Television.

Castro, J. (2000). Tupi. Pioneira da televisão brasileira. Fundação Assis Chateaubriand.

Chamy, C. H. (2014, 3 de setembro). Cómo Turquía está cambiando el mercado de las teleseries de América Latina. $B B C$. https://bbc.in/3iGclYu

$\mathrm{CHV}$ explica las razones de emitir la primera teleserie doblada al "chileno". (2016, 6 de dezembro). El Mercurio. https://bit.ly/2Uw9Yj9

Clark, W., \& Priolli, G. (1991). O campeão da audiência. Uma autobiografia. Best Seller.

Cornelio-Marí, E. M. (2020). Mexican melodrama in the age of Netflix: Algorithms for cultural proximity. Comunicación y Sociedad, 27, e7481. https://doi. org/10.32870/cys.v2020.7481

Coronado, D. (1992, 27 de setembro). David Stivel. El Tiempo. https://bit. ly/2UFrAc7

Cruz, M. F. (2015, 3 de novembro). Claudio Villaroel: 'Hoy la tele es gente que canta, responde preguntas y discute. La Nación. https://bit.ly/3BzTve8

Dávila, A. (2012). Latinos, Inc.: The marketing and making of a people. University of California Press.

Diez años de 'Sabado Gigante'. (1996, 30 de junho). La Reforma, 4.

Ferreira, G. C. (2017). O fenômeno da ficção televisiva turca: A recepção da telenovela Fatmagul no Brasil [Trabalho de conclusão de curso, Universidade Federal do Paraná]. Repositório Institucional da UFPR. https://bit.ly/2Tt5YPF Fraga, N. (2011, 5 de setembro). O filme vai se repetir no Brasil? O Estado de S. Paulo. https://bit.ly/3xVlFOC

Garrett, J. L. (1985). The Beagle Channel dispute: Confrontation and negotiation in the Southern Cone. Journal of Interamerican Studies and World Affairs, 27(3), 81-109. https://doi.org/10.2307/165601

Glória, ditadora das novelas, cai sem lágrimas. (1969, 14 de maio). Veja, (36), 62.

González de Bustamante, C. (2012). Muy buenas noches: México, television, and the cold war. University of Nebraska Press.

Gutierrez, E. (2007). De la tele-visión a la televisión. Signo y Pensamiento, 50(26), 290-291. https://bit.ly/3zqwzw3

Herz, D. (1987). A história secreta da Rede Globo. Tchê!.

Joacogarau (Apresentador). (2015, 2 de maio). Walter Sequeira habló sobre las Mil y Una Noches [Episódio de podcast de áudio]. In Noche de Necios. Radio Zonica. https://bit.ly/3iy2O5C

Kreutzberger, M. (2001). Don Francisco, entre la espada y la pared. Grijalbo. 
La Pastina, A. C., \& Straubhaar, J. D. (2005). Multiple proximities between television genres and audiences the schism between telenovelas' global distribution and local consumption. Gazette, 67(3), 271-288. https://doi. org/10.1177/0016549205052231

Machado de Assis, E. (2000). O brasileiro mais brasileiro. In J. A. Castro (Ed.), Tupi. pioneira da televisão brasileira (p. 20). Fundação Assis Chateaubriand.

Mattelart, A. (1973). Agresión desde el espacio: Cultura y napalm en la era de los satélites. Siglo XXI.

Melo, J. M. (1987). Cultura brasileira: Temas e situações. Ática.

Mora, G. C. (2011). Regulating immigrant media and instituting ethnic boundaries - The FCC and Spanish-language television: 1960-1990. Latino Studies, 9(2-3), 242-262. https://doi.org/10.1057/lst.2011.20

Muñoz, J. A. (2011, 19 de setembro). Los obstáculos que encontrará Netflix en América Latina. CNN. https://cnn.it/3rrTtAF

Oliveira, J. B., Sob. (2011). O livro do Boni. Casa Da Palavra.

Owens, D. (1988, 3 de outubro). Joaquin Blaya va vendiendo el mercado hispano. El Nuevo Herald, 1.

PRODU. (2016). Conversación con Patricio Hernández CEO de Mega Chile y su éxito [Vídeo]. YouTube. https://bit.ly/2Tx49Bq

Ribke, N. (2013). The genre of live studio audience programmes in a political context: The Flavio Cavalcanti Show and the Brazilian military regime. Screen, 54(3), 355-370. https://doi.org/10.1093/screen/hjt022

Ribke, N. (2020a). Telemontecarlo as a (failed) Italo-Brazilian communications experiment: South-South transnational business, politics and culture (19851994). Media History, 27(3), 364-380. https://doi.org/10.1080/13688804.2 020.1801402

Ribke, N. (2020b). Transnational Latin American television: Genres, formats and adaptations. Routledge.

Rivero, Y. (2012). Our Betty: The legacy of Yo soy Bety, la fea's success in Colombia. In J. McCabe \& K. Akass (Eds.), TV's Betty goes global: From telenovela to international brand (pp. 45-61). Bloomsbury Publishing.

Sanchez, E. (2019, 21 de março). Los mejores países de América Latina para ver Netflix Merca2.0. https://bit.ly/3kOagN0

Sinclair, J. (1998). Latin American television. A global view. Oxford University Press.

Sinclair, J. (2005). Latin American commercial television: "Primitive capitalism". In J. Wasko (Ed.), A companion to television (pp. 503-520). Blackwell. 
Sinclair, J. (2014). Transnationalization of television programming in the IberoAmerican Region. MATRIZes, 8(2), 63-77. http://dx.doi.org/10.11606/ issn.1982-8160.v8i2p63-77

Sirvén, P. (1996). El rey de la TV: Goar Mestre y la historia de la televisión. Clarin Aguilar.

Sousa, H. (1997, 2-7 de julho). Crossing the Atlantic: Globo's wager in Portugal [Artigo apresentado]. Conferência da International Association for Mass Communication Research, Oaxaca, Mexico. https://bit.ly/3rvQsiP

Straubhaar, J. D. (1991). Beyond media imperialism: Assymetrical interdependence and cultural proximity. Critical Studies in Media Communication, 8(1), 39-59. https://doi.org/10.1080/15295039109366779

Straubhaar, J. D. (2007). World television: From global to local. SAGE.

Suar, A. (Criador e produtor). (2015-2016). Esperanza mía [Telenovela]. Pol-ka. Turow, J. (1997). Breaking up America: Advertisers and the new media world. University of Chicago Press.

Varela, M. (2005). La televisión criolla: Desde sus inicios hasta la llegada del hombre a la Luna, 1951-1969. Edhasa.

Vassallo de Lopes, M. I., \& Greco, C. (2016). Brasil: A TV "transformada" na ficção televisiva brasileira. In M. I. Vassallo de Lopes \& G. Orozco Gómez (Eds.), (Re)invenção de gêneros e formatos da ficção televisiva: Anuário Obitel 2016 (pp. 135-176). Sulina.

Villar Gertner, A. (2014). The Beagle Channel frontier dispute between Argentina and Chile: Converging domestic and international conflicts. International Relations, 28(2), 207-227. https://doi.org/10.1177/0047117814526910

Wallach, J. (2011). Meu capitulo na TV Globo. TopBooks.

Artigo recebido em 19 de julho de 2021 e aprovado em 6 de agosto de 2021. 